\title{
Quality and Safety in PICU and NICU: Scoreboard Control and Care Network
}

\author{
Fuster-Jorge, P.A.1, 4 , Fernández-Sarabia, J. ${ }^{1}$, Delgado-Melián, T.2, \\ Pérez-Hernández, R.1 Jiménez-Rivera J.J. ${ }^{3}$, Montes de Oca-Afonso M.R. ${ }^{5}$, \\ Domenech-Martínez, E. ${ }^{4}$ and Sierra-López, A.2, 4 \\ ${ }_{1}^{1}$ Pediatric Department and Neonatology Section-NICU and PICU, \\ ${ }^{2}$ Microbiology and Preventive Department, \\ Intensive Medicine Department, \\ ${ }^{4}$ Canary University Hospital, La Laguna University Medicine School, \\ ${ }^{5} \mathrm{Ofra}$ Medical Emergencies Service, \\ Santa Cruz de Tenerife, \\ Spain
}

\section{Introduction}

\subsection{Quality and safety: EFQM application to a health care organization}

To ensure that each patient receives the best feature set to achieve an optimal process, to achieve the best possible results with minimal iatrogenic (safety) and the highest satisfaction, where the analysis of economic costs should also be able (efficiency and adequacy economic), defined according to the World Health Organization (WHO, 2010) the overall quality of the institutions, services and health units. All this is included in the organization of health care providers in a quality management system, comprehensive processes that will be compared with a model of excellence based on the best available evidence (Evidence-Based Quality Improvement) and patient-led (What?, Why? and for Who?), in order to learn, innovate, and to the formall and continuous improvement of the structure, both professional and technical, and to the full satisfaction of the professionals involved, patients or clients and global society, which must be assessed through surveys of specific satisfaction.

To achieve these goals the following are required: an adequate computer systems to record all the activity information of the health maintenance organization (intranet) and the processes offered or RDG (Relationship Diagnosis Group); a broad consensus with a full continuum involvement of all professionals (to Want, to Know and Empowerment) and community (clients and society); information and time and smooth communication between everybody involved; training and recognition of all professionals, groups formation with them in order to achieve improvement missions (What?, How? and Why?), to develop the map and diagrams of each process, carrying out the surveillance and control of key indicators (self), quantifying the results and establishing the appropriate corrective in the areas of greatest impact (Benchmarking), (CgestiónE/I, 2010; EFQM, 2010; EVALUACIONEFQM, 2010; Guía de la calidad, 2010; Moracho, 2003). 
The process methodology is based on the model of excellence from the European Foundation for Quality Management (EFQM, 2010), founded in 1988 with the support of the European Commission, adapted to our area's prior references Malcolm Baldrige Model (USA) and Premium Deming (Japan), (WHIKIPEDIA, 2010). The EFQM to compare the organization with a model to learn and improve continuously, evaluating the quality of the management carried out, identify areas for improvement and establish ratings. This model includes PDCA cycles (Plan-Do--Control-Act)) with successive actions, and repeated standardized planning, implementation, evaluation and correction. For this and all levels of the health organization, an ongoing assessment of each process will be devloped, conducting regular internal controls (self) and external (audit), all of which will compare our results with the model set (Moracho, 2003), which in the field of health is achieved not only by consulting the references published in our area for evidence-based medicine, but also by participating in multicenter care networks results that include related health care services, which in our cases are pediatric and neonatal intensive care, activity that we have always considered an excellent tool in our work and support care duties, teaching and researching.

\subsection{Intensive care in pediatric and neonatal medicine: the PICU and NICU}

Intensive care medicine was born in the decade of the $60 \mathrm{~s}$ in response to social and welfare needs of reducing mortality and the number and importance of disability that originated, and it is still produced at present, critical situations potentially reversible. To this end the intensive care units (ICU) were created in specific areas of hospitals, in order to focus on these human and technical resources required to ensure top-quality care, effective and efficient. The first adult ICU was created in the U.S., Baltimore (1958) and Pittsburgh (1961), while in Spain it was a pioneer who created it in 1963 by Professor Jiménez Díaz in La Concepción Clinic (Madrid).

In Europe, pediatric and neonatal intensive care since 1980 had its own society in the European Club of Paediatric Intensive Care (ECPIC), since 1998 became the current European Society of Paediatric and Neonatal Intensive Care (ESPNIC, 2010), that it supports a close relationship with the European Society of Intensive Care Medicine (ESICM). The ESPNIC is an organization dedicated to promote and advance the art and science of pediatric and neonatal intensive care based on evidence, and to meet the needs of this client group so important in the European and international health context.

The pediatric intensive care constitutes a specific area of knowledge of national and international prestige. The PICU is the main framework for action, although not the only one, with a very specialized care for critically ill patients within the pediatric departments and pediatric services. Pediatric intensive care physicians have the right and duty to participate in care, teaching and researching of critical child care wherever they are, that is in any of the various levels of the health care. Also in the early 60s the first PICU was created in parallel with the tremendous growth experienced in those years in the field of surgery and other pediatric specialties. In Spain, the first one was created in the mid-60's Children's Hospital Vall d'Hebron (Barcelona); after the development of these units, they have been extended by almost all the national territory. In our country, the Spanish Society of Pediatric Intensive Care (SECIP, 2010), was founded over 25 years ago, preceded in 1976 within the AEP by the Pediatric Intensive Care Section, joining in 1980 as the Pediatric Group Spanish Society of Intensive Care Medicine and Coronary Units (SEMICYUC). The SECIP is a nexus of scientific participation and support in the organization of pediatric intensive care in Spain, and it maintains a close relationship with other companies and 
networks of intensive care outcome of pediatric and adult outcomes, both domestic and international. However, even in our country, there is only the recognition and accreditation as a specialty itself by the Spanish Association of Pediatrics (AEP, 2010), although we hope to obtain recognition of the National Council of Medical Specialties, with the creation of a specific training area (STA).

The hospital neonatal intensive care units (NICU) are pioneering highly specialized units, which preceded the pediatric units. They served with the highest level of care to babies born very prematurely or whit severe disease. They have also evolved greatly over the past 30 years, gradually implementing the concept of regionalization in perinatal care planning and to introduce the concept of definitive evidence-based medicine. Gradually units have proliferated in both high-risk obstetric and the modern tertiary NICU in reference hospitals from our extensive regional and national healthcare network, establishing a perinatal medical transport system better and more specialized training for all professionals involved in maternal-fetal and neonatal assistance.

In recent decades there has been an increase in the number of premature births. Its causes are multifactorials, affecting socio-economic factors, older age of parents or in vitro fertilization techniques, among others. In parallel, there has also been a significant increase in the birth rate and survival of newborns with very low birth weight (VLBW), weighing $<1500$ grams, which is generally associated with subpopulation very premature (29-33 weeks gestation), or even extremely premature (23-28 weeks gestation), so his stay in the NICU is often very long, thus consuming $65 \%$ of health resources for global neonatology practice (Rogowski et al, 2001).

Simultaneously, there have been extensive advances, preventive, therapeutic, diagnostic and technology, in neonatal, perinatal and obstetric medicine. The achievements and collected welfare improvements have been numerous, some of these advances in neonatology, including the use of surfactant in the treatment and prevention of respiratory distress syndrome of the newborn and new forms of respiratory support and ventilation (high frequency ventilation, extracorporeal membrane oxygenation, inhalator nitric oxide, liquid ventilation, etc.) have also subsequently been successfully used in pediatric and adult critical care patients.

The advances that have had more influence and profit in the NICU are: the widespread use of antenatal corticosteroids to achieve fetal lung maturity prior to preterm birth $<34$ weeks gestation; the selective and early postnatal administration of exogenous pulmonary surfactant in very premature; the emergence and development of new forms of mechanical ventilation, invasive or noninvasive, with more protection to avoid injury in the immature lungs and that facilitate early extubation; the improvements made in nutrition and infant feeding, with emphasis on early enteric and progressive human milk nutrition; and finally, the universal implementation of the delivery process of care focused on the development of the newborn and his family. All this has greatly improved our results in the short, medium and long term time, mainly in the VLBW, reducing their stay in the NICU and the hospital, morbidity and mortality, thus obtaining a longer survival with a sufficient and satisfactory quality of life.

To improve the care given in these units, it is necessary to identify risks that have our local population, controlling the results too. This is essential to establish a registration system that allows self-management results, especially in newborns that have more biological and social risk. So, we know our trends in mortality, morbidity and disability among survivors, in short, medium and long term, in various biological areas but particularly in the infants neurodevelopment. 
In addition, our results should be compared with other similar units in their provision of professional human resources, technical and level of care complexity. To this end, in 2002 the database of neonatal units SEN 1500 (SEN1500, 2010) was created. This is a multicenter network created as a specific working group of the Spanish Society of Neonatology (SEN, 2010), with the aim of improving the quality and safety of newborns and their families, through research programs, education and improvement of cares received. It consists of 92 hospitals, many with III-B level of care, similar to our NICU, and distributed throughout the Spanish geography. It has a central computerized database which identifies the risks in this population, assesses the results of morbidity and mortality in the short and long term and researches in the field of neonatology. The Spanish Society of Neonatology has its origins in the historical heart of the Spanish Association of Pediatrics (AEP, 2010), when the Section of Perinatal Medicine was first created, and it established relations with the European Society of Perinatal Medicine and obstetricians of the Spanish Society of Gynecology and Obstetrics (SEGO) interested in perinatology. In 1997 the Spanish National Commission Specialties include the Neonatology in its catalog, setting specific training accreditation (STA) through the AEP.

For many years, this type of network data systems is also available in different countries and communities, some with extensive international involvement. Of these, the most popular are Australian and New Zealand Neonatal Network, British Association of Perinatal Medicine, Canadian Neonatal Network, European Neonatal Network (EuroNeoNet), International Neonatal Network, National Institute of Child Health and Human Development (NICHD) Neonatal Research Network, and Vermont Oxford Network (VON).

In our NICU, while continuing to adapt the recommendations, protocols and standards established by the SEN and other neonatal societies and associations, mainly European and North American. For many years in our NICU conducted a monthly analysis. Our results since 2002 have been compared with annual report of Spanish network SEN1500, ad hoc working group of the Spanish Society of Neonatology; and since 2005 we can compare with the monthly report of the international Vermont Oxford Network (VON, 2010), consisting of 850 units worldwide, mainly from USA, Canada and Europe, where we participate individually and into the newest member SEN1500 Spanish Group, which encompasses 11 Spanish hospitals. Also, in January 2009 our NICU was accepted to participate in the European Neonatal Network (EuroNeoNet, 2010), belonging to the European Neonatal Information System, which includes the project and initiative EuroNeoStat and EurNeoSafe; EuroNeoNet is Affiliated to European Society for Paediatric Research (SPR) and to European Society for Neonatology (ESN). Surely our extensive involvement in all these networks has enabled us to detect and correct deficiencies identified progressively in our business, continually improving quality and safety of our newborns and infants.

The Canary University Hospital (HUC) is a health care, teaching and research tertiary reference center, located in the Northern Area of the Tenerife Island and belonging to the public hospital network of the Canary Islands in Spain. It has 665 beds and is located next to the Medicine School in the San Cristóbal de La Laguna City; and provides medical coverage to refer a general population of children with an average rate of $19.7 \%$ and a population aged < 15 years of 66.986 children: dates from Canary Statistical Institute , 2000-2006 (ISTAC, 2010).

In our hospital many years ago we began the policy of functional standards, proposed in the U.S. since 1951 by The Joint Commission (The Joint Commission, 2010), to improve the quality and safety of patient-centered care. Also, in our Department of Neonatology, 
encompassing the PICU and NICU, we began this new line of work. Since then, we have developed a comprehensive and progressive master plan with specific strategies and policies for processes that we consider most at risk, focusing our NICU and PICU in developing not only the patient but also in their family. It was not an easy task, but very satisfying. Even today, we want to and can improve a lot, we are constantly learning, innovating and we know that we have a long way to go to move closer to excellence. However, sometimes we are quite confused and tend to justify, when the results of ours evaluations show an imbalance between the model of excellence and the daily clinical reality. "The perfection of methods and confusion of goals seem to characterize our age" (Albert Einstein).

It would be very long to detail each of the strategies currently being carried out in our two intensive care units. Therefore we only summarize statement of two processes that we consider most relevant to our NICU and PICU: surveillance and control of nosocomial infections; and prompt use of the expiratory pressure and ventilation support noninvasively in newborn with very low birth weight.

\section{Surveillance and control of nosocomial infections in ours PICU and NICU}

Nosocomial infections (NI), are associated or related to health care, and represent a major public health problem in pediatric intensive care units (PICU) and neonatal (NICU) too, by causing high morbidity and mortality, a significant increase in hospital stay and generate increased health care costs (Centers for Disease Control and Prevention (CDC), 2010; Raymond, Aujard \& the European Study Group, 2000; Lodha et al, 2001; Stover et al, 2001; Grohskopf et al, 2002; Urrea et al, 2003, Edwards et al, 2005). Therefore, epidemiological surveillance and prevention must be considered fundamental objectives of quality and safety of pediatric and neonatal critical patient care.

In hospitalized adult patients the NI figures reach 5-10\% according to data from the CDC (Yokoe, 2008). These figures are even higher in the pediatric intensive care patients and the prospective European study of UCIP reveals an incidence reaching 23.5\% (Raymond, Aujard \& the European Study Group, 2000). In the neonatal intensive care these figures are even higher if we take into account the higher risk newborn, the extreme low birth weigh (ELBW $<1000$ grams), in who we find figures of incidence over $40 \%$, both in Europe and USA. (Beth et al. 2001; Geffers et al 2008). Being aware of their impact, monitoring and control of nosocomial infections have been a priority in our units.

Thus, since 2000 the HUC Department of Microbiology and Preventive Medicine conducted surveillance in our PICU and NICU, following the "Specific Program for Surveillance of Nosocomial Infection in Spain" (PREVINE, 2010), launched by Spanish Society of Preventive Medicine, Public Health and Hygiene. Through surveillance we obtain various indicators, the most interesting being those that relate the days of use of devices (urinary catheter, mechanical ventilation and intravascular devices) with the same associated infections (urinary tract infection, pneumonia and bacteremia). These indicators are also used by the NNIS (National Nosocomial Infections Surveillance System Report ((NNIS), 2003), which since 2005 is integrated into the NHSN (National Healthcare Safety Network, Edwards et al, 2007). As a result of monitoring, we have obtained a set of indicators that are disseminated to the PICU and NICU staff. From this information it was established a line of action against the nosocomial infection that included preventive guidelines, which have been developed based on the best scientific evidence available for that, such as the CDC in USA (Centers for Disease Control and Prevention (CDC), 2010). 
Specific recommendations for neonatal intensive care units have been issued (Figure 1), whose methodology is based on the detection of centers of excellence, identification and grading of public practice, its implementation in short cycles of "plan-do-study-act" and the psychological implications of all staff. The results obtained with its progressive implementation in neonatal units have been excellent (Kilbride et al, 2003).

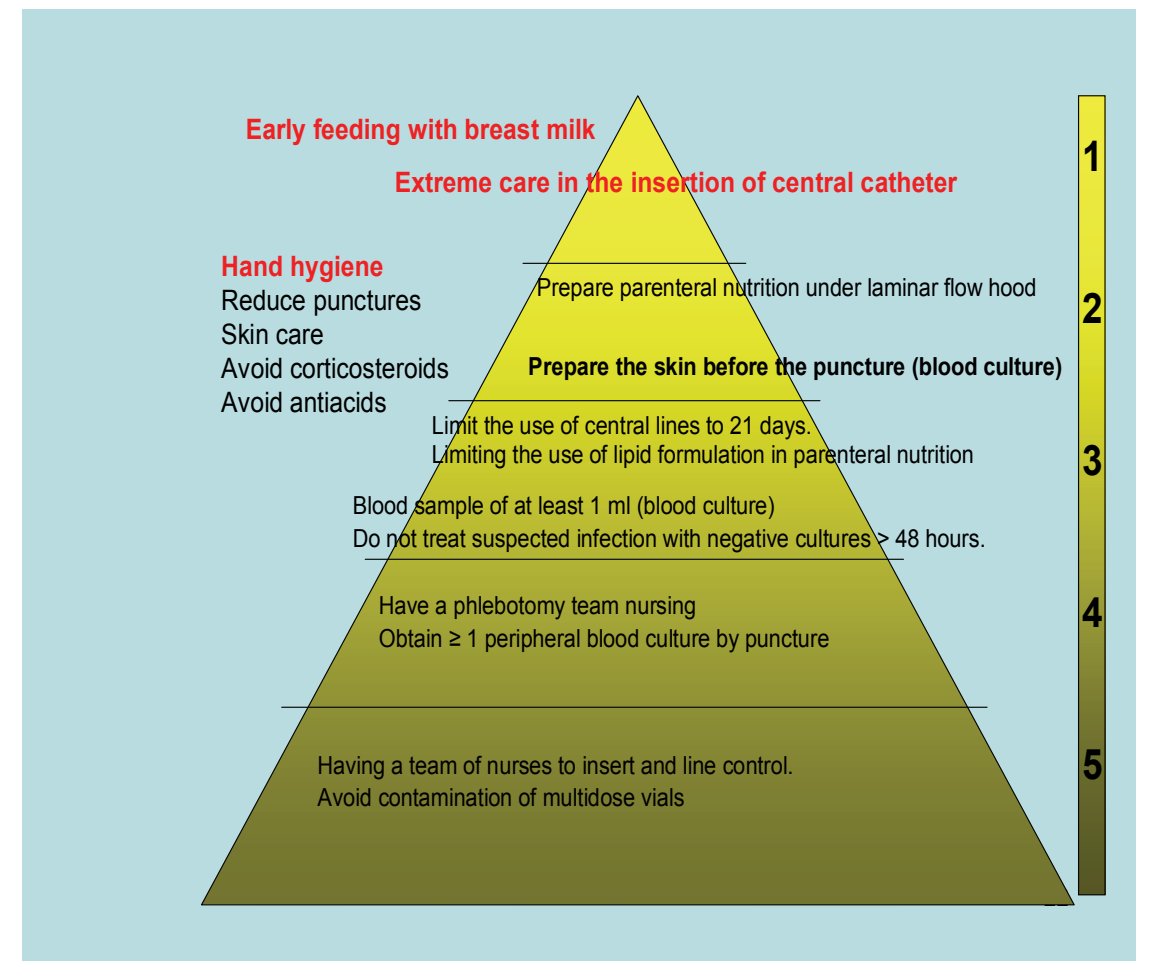

Fig. 1. Potentially beneficial practices (BPP) based on the best scientific evidence available (evidence grade 1-5), for the prevention of nosocomial infection in the NICU. Source (modified): "Evidence-Based Quality Improvement in Neonatal and Perinatal Medicine: The NIC / Q 2000 Experience" (Kilbride et al, 2003)

In addition to the NNIS, the NCID (National Center for Infectious Diseases, 2010; Edwards et al, 2007) and now the NHSN have represented over the years our most important references in infectious diseases epidemiology and preventive fields.

In our hospital we had clear since 1997 that the NI could create a problem in the new PICU of HUC, given its direct high morbidity and mortality, the increase of the stays in hospital and the economic costs at other similar units. In addition, our PICU was the first of these units opened in our island province of Santa Cruz de Tenerife, as well as our reference area, we cover for many years all our health area of influence.

The NI has been a critical priority that we controlled and analyzed continuously working with the Department of Microbiology and Preventive Medicine, relating to the proper use of invasive techniques of greater risk. We prospectively collected the main epidemiological data (number of days of hospitalization, use of intravascular devices, closed urinary catheter 
and mechanical ventilation) and the occurrence of related nosocomial infections (bacteremia, pneumonia and urinary tract infection).

This monitoring takes on new significance in the neonatal intensive care units. The patients seen in it, especially the lower gestational age and birth weight at high risk for nosocomial infection as already discussed. This is due to their immaturity (minor immune function, impaired skin and gastrointestinal barriers) and their NICU longer stay days (mayor bacterial and fungal colonization, central venous catheters, parenteral nutrition and invasive manipulation). In our neonatal intensive care unit there has been a cumulative incidence(CI) of nosocomial infection (number of patients with nosocomial infections $\times 100$ / total number of patients studied) in high risk patients (defined as those with umbilical catheter, mechanical ventilation, treaties potentially serious diseases, surgically and weighing less than 1500 grams) of $46.15 \%$ in $2007,44.30 \%$ in 2008 and $43.02 \%$ in 2009 ; and if we consider only newborn less than 1000 grams this figure rises to $50 \%$ in the last year; and $54 \%$ if you count the newborn less than 32 weeks in the same period of time. Of all these NI over the past year, 33.7\% were bacteremias (sometimes associated with intravascular devices), 31.4\% skin infections, $12.8 \%$ eye infections and $10.5 \%$ pneumonia (associated or not with mechanical ventilation). The most common microorganisms found where: $15 \%$ Staphylococcus epidermidis, $11.5 \%$ Enterobacter cloacae, Enterococcus faecalis, Pseudomonas aeruginosa and Candida parapsilosis.

To be our pediatric unit a new PICU created since 1997, we prioritize it at the first years of the study. It is an autonomous medical and surgical pediatric intensive care unit of level III-B; it has 4 beds in single box that generates annual revenue of more than 300 patients. During the study period we had 1031 stay days per year, with $65.93 \%$ of male patients, a mean age of 3.4 years (SD \pm 4.26 and range $0-15) .73 \%$ came from the emergency unit, $7 \%$ from others areas of pediatric and neonatal hospitalization, $10 \%$ from the surgical area and the remaining $10 \%$ were outside patients. $46 \%$ had respiratory disease, $19 \%$ infections, $12 \%$ neurological diseases, $10 \%$ trauma injuries, $6 \%$ cardiovascular diseases and $2 \%$ oncohematologic diseases. The incidence of one or more organ failure was 31\% (respiratory 39\% and cardiovascular $34 \%$ ) and of multiorgan failure was 13\%; with an average severity index of 5.52 (0-26) for the PSI (Physiologic Stability Index) and 5.9 (0-41) for the PRISM (Pediatric Risk of Mortality Score), which in $26 \%$ was $>10$. Of all patients $39 \%$ required only monitoring and conventional treatment, $9 \%$ analgesic-sedation for invasive procedures, $64 \%$ central vascular catheter, $37 \%$ mechanical ventilation, $17 \%$ hemodynamic support and $1.8 \%$ extrarrenal depuration techniques; with a half therapeutic effort class II $=13$ (range 0-50) for TISS (Therapeutic Intervention Scoring System), that also in $26 \%$ was $>20$ (class III-IV), according to the severity of our patients referred to PRISM. Our average stay days was 5.7 (SD \pm 8.26 ), with an occupancy rate of $85 \%$ and a rotation rate of $42.8 \%$. The mortality was $3.30 \%(33 \%$ of all deaths where organs donors); the incidence of patients with severe sequelae was $1.5 \%, 9 \%$ of them needed readmissions; and we had a small number of complaints (0-1/year).

During PICU surveillance conducted from 2000 to 2004 were analyzed a total of 302 patients, a NI cumulative incidence of $9.76 \%$ was found. The most frequently isolated microorganisms were bacilli Gram negative (46.60\%), followed by Candida spp $(33.30 \%)$ and cocci Gram-positive $(20.1 \%)$. Predominant localization was as usual the bacteremia, with a partial cumulative incidence (PCI) of $4.09 \%$, mainly primary face of intravascular devicerelated $(2.99 \%$ vs. $1.10 \%)$. Tables $1-2$ show our results in $2000-2004$ for central catheterassociated bacteremia and their use rates, compared with data published by the NNIS (the National Nosocomial Infections Surveillance System Report (NNIS), 2003). 


\begin{tabular}{|c|c|c|c|c|c|c|c|c|c|}
\hline \multirow[t]{2}{*}{ Year } & \multirow{2}{*}{$\begin{array}{c}\mathrm{N}^{0} \text { of patients } \\
\text { with } C C\end{array}$} & \multirow{2}{*}{$\begin{array}{c}\mathrm{N}^{\circ} \text { of } \\
\text { catheter- } \\
\text { related } \\
\text { bacteremia }\end{array}$} & \multirow{2}{*}{$\begin{array}{l}\text { Days } \\
\text { of CC }\end{array}$} & \multirow{2}{*}{$\begin{array}{c}\text { Tasa de } \\
\text { incidencia } \\
\text { del HUC }\end{array}$} & \multicolumn{5}{|c|}{ NNIS Rates, June 2003} \\
\hline & & & & & Average & $25 \%$ & $50 \%$ & $75 \%$ & $90 \%$ \\
\hline 2000 & 13 & 2 & 108 & 18.52 & \multirow[t]{6}{*}{7.3} & \multirow[t]{6}{*}{3.8} & \multirow[t]{6}{*}{5.9} & \multirow[t]{6}{*}{8.8} & \multirow[t]{6}{*}{11.5} \\
\hline 2001 & 24 & 3 & 215 & 13.95 & & & & & \\
\hline 2002 & 33 & 4 & 302 & 13.25 & & & & & \\
\hline 2003 & 59 & 1 & 452 & 2.21 & & & & & \\
\hline 2004 & 29 & 2 & 268 & 7.46 & & & & & \\
\hline Total & 158 & 12 & 1345 & 8.92 & & & & & \\
\hline
\end{tabular}

Table 1. Central catheter (CC)-associated bacteremia in the HUC PICU and references ${ }^{*}$ ) National Nosocomial Infections Surveillance (NNIS) System Report, data summary from January 1992 Through June 2003, issued August 2003. Am J Infect Control 2003; 31:481-98. Quartils: 25\%, 50\%, 75\% and 90\%. Rate of central catheter-associated bacteremia $(\%)=$ number of bacteremias associated with CC x 1000 / number of days of CC use

\begin{tabular}{|c|c|c|c|c|c|c|c|c|c|}
\hline \multirow[t]{2}{*}{ Year } & \multirow{2}{*}{$\begin{array}{c}\mathrm{N}^{\circ} \text { of patients } \\
\text { with } C C\end{array}$} & \multirow{2}{*}{\begin{tabular}{|l|} 
Stay Days \\
in Hospital
\end{tabular}} & \multirow{2}{*}{$\begin{array}{c}\mathrm{CC} \\
\text { Days } \\
\text { use }\end{array}$} & \multirow[t]{2}{*}{ Use Rate } & \multicolumn{5}{|c|}{ NNIS Rates, June 2003(*) } \\
\hline & & & & & Average & $25 \%$ & $50 \%$ & $75 \%$ & $90 \%$ \\
\hline 2000 & 31 & 235 & 108 & 0.46 & \multirow[t]{6}{*}{0.46} & \multirow[t]{6}{*}{0.30} & \multirow[t]{6}{*}{0.41} & \multirow[t]{6}{*}{0.53} & \multirow[t]{6}{*}{0.60} \\
\hline 2001 & 35 & 301 & 215 & 0.71 & & & & & \\
\hline 2002 & 65 & 455 & 302 & 0.66 & & & & & \\
\hline 2003 & 91 & 690 & 452 & 0.66 & & & & & \\
\hline 2004 & 41 & 373 & 268 & 0.72 & & & & & \\
\hline Total & 263 & 2054 & 1345 & 0.65 & & & & & \\
\hline
\end{tabular}

Table 2. Use of central venous catheter (CC) in the HUC PICU and references $\left(^{*}\right)$ National Nosocomial Infections Surveillance (NNIS) System Report, data summary from January 1992 Through June 2003, issued August 2003. Am J Infect Control 2003; 31:481-98. Quartils: $25 \%, 50 \%, 75 \%$ and $90 \%$. CC utilization rate $=$ number of CC use days / number of stay days 
In the same time period, the PCI of ventilator-associated pneumonia was $1.80 \%$, with a mechanical ventilation utilization rate of 0.27 days (mechanical ventilation days/total stay days) and the PCI of urinary tract infection associated with the closed urinary catheter was $2.63 \%$, with a utilization rate of 0.37 (closed urinary catheter days / total stay days).

The main conclusions obtained after this first period of the study were the following: the NI is certainly a problem in our pediatric intensive care unit, although smaller than in the neonatal unit; and bacteraemia was the predominant NI, it's related to an excessive time use of intravascular devices (central venous catheters). These comparative results helped to understand their impact on later to direct time and improvement strategies to reduce infectious morbidity: "Guidelines for the Prevention of Infections Associated with Intravascular Devices in Pediatric and Neonatal Patients" (2005); and reinforcement of the "Hygiene Program Hands ", repeating once or twice a year specific training courses for all the health personnel of neonatology and other pediatric areas too. Over the years, as shown in Figure 2, we have to improve our performance, not only in the PICU, but also and simultaneously in the NICU and other hospital neonatal units (medium and minimum cares). Nosocomial bacteremia has been steadily decreasing, but still it has a long use days rate of these invasive devices.

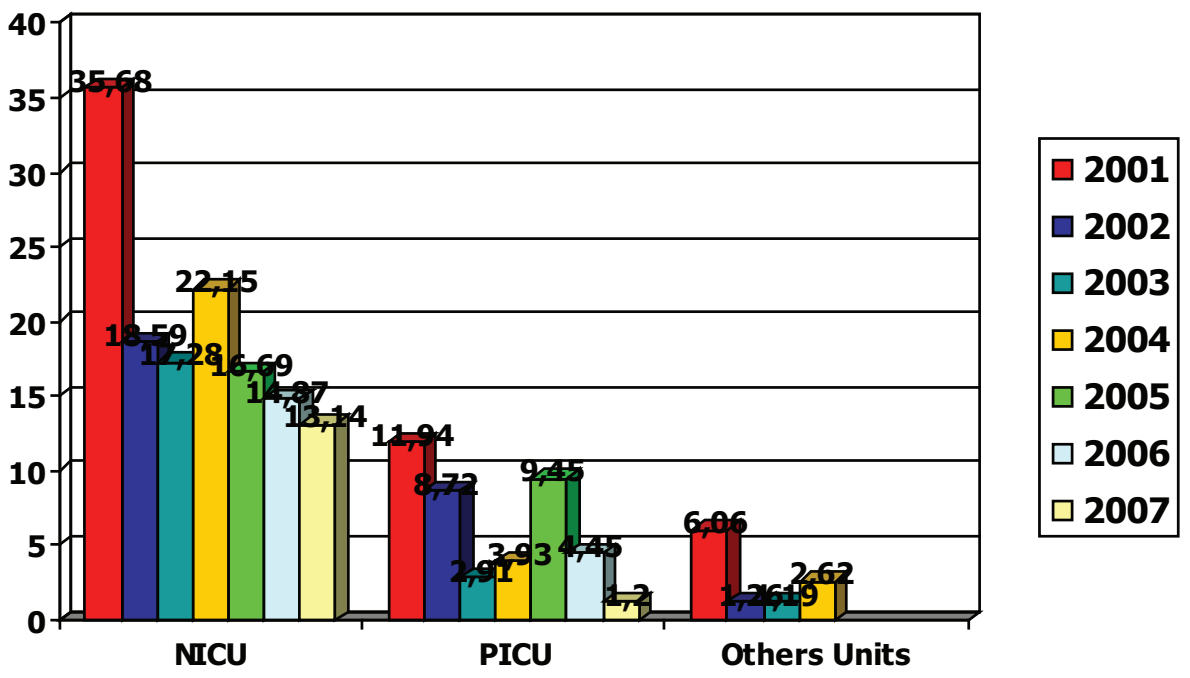

Fig. 2. Nosocomial bacteremia incidence density in the HUC neonatal units (2001-2007). Incidence Density: DI $(\%)=\mathrm{N}^{\circ}$ of bacteremia x 1000 / total stays days

Currently, following the program developed by the U.S. John Hopkins Hospital and recommendations established by the WHO, the Spanish Health Ministry and the Canary Islands to the intensive care of adults, we adapted and planning an ambitious strategic plan "Bacteremia zero" (Bacteremia zero 1st edition, 2009) which attempts to reduce the incidence of bacteremia intervention is based on two main critical points to reduce related bacteremia 
with central venous catheters: proper hand hygiene all the care team, medical students, family and visitors, and the proper use of intravascular catheters.

As bacteremia, whether or not the use of intravascular devices, are the leading cause of nosocomial infection in many units, both in our country (Urrea Ayala, 2007) and outside it, we should establish corrective measures to improve our results. Bacteremia associated with central venous catheters is caused mainly by coagulase-negative Staphylococci and others colonizing the skin around the insertion point of germs transmitted by the manipulation of the ICU staff. Moreover bacteremia are related to bacterial translocation from the intestinal reservoir. Thus both the care of central catheters, modification of bacterial colonization of the newborn and hygiene in the handling of this risk population have become primary goals in ours UCI.

\subsection{Improve the management of central venous catheters}

There are several strategies that can be taken to reduce infections associated with intravascular devices, and usually is a set of them which we must take to achieve a reduction in nosocomial infection. Therefore have been established for good clinical practice guidelines, based on the best available evidence and adapted many times for adult medicine, with proven results even in neonatal units that have achieved lower the number of infections (Aly, 2005). In this package includes not only those related to the act itself of catheter placement (choosing the right place, correct use of hand hygiene, barrier precautions such as gowns, caps, gloves and mask, a team of sufficient or proper disinfection of the skin) or maintenance (minimizing the number of entries, disinfect with alcohol keys to manipulate them, change dressings have become wet, dirty or rise, or every 7 days failure to fulfil the above, currently using chlorhexidine to clean the entry point), but should be reviewed since the indications for placement, the criteria for withdrawal or clarify the definitions of catheter-related infection to compare our results with historical series or with other institutions or networks (O' Grady, 2002).

\subsection{Manipulation of bacterial and fungal colonization of the newborn}

Bacterial and fungal colonization in neonatal units is related to the presence of bacteremia, sepsis and necrotizing enterocholitis in later stages. This bacterial colonization is associated with early onset and type of feeding, prematurity itself, the bacterial flora exists in each ICU and the use of broad spectrum antibiotics. For this reason the modification of the colonization of the newborn has set itself a target for the reduction of nosocomial infection. Basically there are two strategies in this regard have been introduced in recent years: the modification of intestinal bacterial colonization, with the confirmation of the importance of breastfeeding as the primary food for all newborns, and mainly for the more immature, and use of probiotics. On the other hand it's the use of antifungal prophylaxis for fungal colonization.

The feeding conditions the type of intestinal colonization. The fetal gut is sterile, whereas the adult has more than 400 bacterial species, giving it a stable environment where there is hardly room for new species (Edwards et al, 2002). The intestinal flora of breastfed infants is mainly composed of bifidobacterium and lactobacillus, while that of formula-fed infant contains more bacteroides, clostridia and enterobacterias (Balmer \& Wharton, 1989; Fay \& Faries, 1975). And we know that this bacterial flora it's most beneficial to the newborn and 
it's associated with a reduction in mortality, sepsis and necrotizing enterocholitis. Breastfeeding achieves this in several ways: immune factors present in breast milk as IgA and lysozyme inhibits the growth of certain bacterias; the acidic $\mathrm{pH}$ of breast milk promotes growth of lactobacillus and bifidobacterium; breast milk has low concentrations of free iron, but contains lactoferrin, which binds iron and facilitates its absorption, thereby decreasing the amount of iron available in the colon, which favours the growth of bacteroides and enterobacterias. It also has bifidogenic factors (prebiotics) nonabsorbable oligosaccharides (lactose centre, with $\mathrm{N}$-acetyl-glucosamine, galactose and sialic acid). This is why breastfeeding is undoubtedly the most physiological change colonization of the newborn intestinal flora towards a more favourable, thereby reducing the risk of nosocomial infection. It's therefore essential that in the NICU there is a training and awareness of all professionals for information, support and monitoring of breastfeeding.

As an alternative to "favourable" bacterial colonization that breastfeeding produces such good results, since 15 years there are pioneer randomized studies that pretending to demonstrate the reduction of NEC and mortality with the use of probiotics for intestinal flora modification in VLBW (Kitajima, 1997; Dani, 2002). After them a great number of metaanalysis have consolidated the results of initial studies, demonstrating that the use of probiotics reduce the incidence of necrotizing enterocholitis (Schanler, 2006; Deshpande, 2007; Deshpande, 2010) and death in newborns, with few side effects and health risks for them, although all these studies, and the latest Cochrane review (Alfaleh, 2008), conclude that further studies will be necessary in neonates, because them should clarify the use of probiotics, their class and administered doses. Although the scientific evidence seems to favour the use of probiotics, however these doubts must be clarified and by this in our unit hasn't started this prevention strategy.

Another initiative for the modification of newborn natural colonization in the NICU is the use of antifungal prophylaxis. Preterm newborn admitted to NICU are more likely than the terms neonates to be colonizationed by Candida spp. Colonization can occur in the gastrointestinal tract (19-30\%), skin and respiratory airway (Saiman, 2006). We also know that others risk factors for invasive fungal infection are: low birth weight, use of central venous catheters, use of antacids, broad-spectrum antibiotics, parenteral nutrition, especially the lipids, and intubation for invasive ventilation (Saiman, 2000). Thus in recent years antifungal therapy has been tried to prevent colonization and invasive fungal infection in those neonates at greatest risk: the extreme low birth weigh less than 1000 grams. The invasives candidiasis have rise too much in all NICU (NNIS, 2003; NHSN, 2005). Candida albicans and parapsilosis are now the third later neonatal sepsis cause, with a highest direct mortality at ELBW. By this fluconazole universal prophylaxis is recommendable by "Clinical Practice Guidelines for the Management of Candidiasis" (Infectious Diseases Society of America, 2009) in newborn of less than 1000 grams birth weigh with rates incidence of $10-15 \%$.

In a comparative studies with historical series (Healy \& Bertini, 2005), fluconazole prophylaxis has shown evidence to reduce the incidence of fungal infection. Despite there is an A1 evidence in their favour by reduce the incidence of invasive candidiasis and enough drug safety, universal prophylaxis is not clearly established because there is some issues still unresolved (Clerihew, 2007; Kaufman, 2010): is more profitable universal fluconazole prophylaxis to control fugal nosocomial infection? ; should be it to give only when NICU 
has a high incidence of invasive candidiasis? Also universal prophylaxis with fluconazole may give to rise species of Candida albicans resistant to fluconazole, or more resistant in others species such as Candida glabrata and even Candida parapsilosis or increase the infections rate by Aspergillus spp. However this trend has been seen in others differences patient populations, such as cancer or transplant patients who receive prophylaxis with fluconazole, but not in the NICU.

In our NICU observational study since 2002-2008, in order to determine the incidence of invasive candidiasis and secondly the need of antifungal prophylaxis, we found that of 19198 live births in our hospital, 1.4\% were VLBW less than 1500 grams (276) and 0.6\% ELBW less than 1000 grams (117). All of newborns had a $0.14 \%$ (27) rates of invasive candidiasis, with $25.9 \%$ of overall direct mortality in the NICU: $22.2 \%$ (6) were neonates with a birth weigh over 1500 grams, with a $16.7 \%$ of mortality; $77.8 \%$ (21) were VLBW less than 1500 grams, with a mortality of $28.6 \%$; and $66.7 \%$ (14) were ELBW less than 1000 grams, with a highest mortality of $35.7 \%$. Therefore our annual incidence in ELBW population varied throughout the study time: $5.5 \%$ in $2002,29.4 \%$ in $2003,16.7 \%$ in $2004,0 \%$ in 2005 , $18.7 \%$ in $2006,8 \%$ in 2007 and $0 \%$ in 2008 .

By the moment we only make a strict control of the invasive candidiasis incidence, because our currently rate is around 7-8\% (2009-2010); and the prophylactic fluconazole $(3 \mathrm{mg} / \mathrm{kg}$ once daily two times at week) is only administrated when our ELBW newborn are colonized or at 7th live days in those with more of one risk factors: venous central catheters, antibiotics, parenteral nutrition or mechanical invasive ventilation.

\subsection{Hand hygiene}

The importance of hand hygiene is making worldwide relevant and need the introduction of a specific hospital protocol for reduction nosocomial infection (Capretti, 2008; Won, 2004). The hands of sanitary staff are the main reservoir and vehicle for transmission of pathogens among patients admitted in the NICU. The concept of hand hygiene is a broader concept than simply disinfecting hands, includes skin care, nails, removing jewellery and artificial nails. This requires adequate use of alcohol solution (Boyce, 2002) or the hand washing with soapy water.

From 2003 the implementation in our units of the use of alcohol solution, as an alternative to hand washing, and the regular holding of workshops for hand hygiene of all health workers have attempted to improve the NI prevention. Although initially it seemed that we were improving, the most recent observational studies on the degree of hand hygiene compliance, carried out annually by the Microbiology and Preventive Medicine Department, results have not changed much and are not yet satisfactory, being similar to those already had published: not achieving a higher degree of overall compliance of 35\%, when the best should be at least $65 \%$ of opportunities for hand hygiene (Table 3 ).

But this we hope that in the next future with the new program tailored "Bacteremia zero" (Bacteremia zero 1st edition, 2009), our two intensive care units will be strengthened definitely the training and involvement of all health workers, seeking higher quality and safety for our patients, improve our performance and achieving increasingly closer to excellence.

As a final conclusion, we believe that the creation of a multidisciplinary working group of infection control, which have involved the Department of Preventive Medicine and ours 
PICU and NICU, has facilitated the implementation of effective measures to control and prevention of nosocomial infection, staff aware of our units need to achieve a steady improvement among all the results, safety and quality obtained.

\begin{tabular}{|c|c|c|c|}
\hline \multicolumn{1}{|l|}{} & $\mathbf{N}^{\mathbf{0}}$ oportunities & $\mathbf{N}^{\mathbf{0}}$ hand hygiene & $\mathbf{\%}$ \\
\hline High risk & $\mathbf{2 2 5}$ & $\mathbf{6 0}$ & $\mathbf{2 6 . 6 6}$ \\
\hline O1 & 197 & 53 & 26.90 \\
\hline O2 & 4 & 4 & 100 \\
\hline O3 & 3 & 0 & 0.00 \\
\hline O4 & 21 & 3 & 14.28 \\
\hline Moderate risk & $\mathbf{2 2 9}$ & $\mathbf{6 6}$ & $\mathbf{2 8 . 8 2}$ \\
\hline O5 & 105 & 33 & 31.42 \\
\hline O6 & 64 & 33 & 51.56 \\
\hline Low risk & $\mathbf{3 8 3}$ & $\mathbf{1 2 9}$ & $\mathbf{3 3 . 6 8}$ \\
\hline O7 & 219 & 44 & 20.09 \\
\hline O8 & 164 & 85 & 51.82 \\
\hline TOTAL & $\mathbf{7 7 7}$ & $\mathbf{2 5 5}$ & $\mathbf{3 2 . 8 1}$ \\
\hline
\end{tabular}

Table 3. Observational study of the completion rate (\%) of hand hygiene in the PICU and NICU of HUC 2007-2009. HIGH RISK: O1 (before direct patient contact), O2 (before inserting central venous catheters), O3 (before inserting peripheral vascular catheters, urinary catheter or other invasive procedures), $\mathrm{O} 4$ (after switching from a contaminated site to another clean in the same patient). MODERATE RISK: O5 (after contact with intact skin of patients), O6 (after contact with body fluids, secretions, mucous membranes, broken skin, drains, bandages and dressings, etc). LOW RISK: O7 (contact with inanimate objects, medication and equipment) clinical) O8 (after removing gloves)

\section{Early nCPAP and NIV in infants of very low birth weight}

In recent decades, several emerging factors such as assisted reproductive techniques, improved obstetric care, the extensive knowledge of physiology and pathophysiology of fetal, perinatal and neonatal cares, and the extraordinary technological advances, diagnosis and treatment in neonatal intensive care have significantly increased the rate of prematurity (newborn less than 37 weeks gestational age). These developments, especially the use of antenatal corticosteroids for lung maturation, the postnatal pulmonary administration of surfactant and the use of invasive ventilation in the management of hyaline membrane disease or neonatal respiratory distress syndrome (RDS) have decreased early morbidity but above all have achieved better survival in the less birth weight (VLBW <1500 grams, ELBW $<1000$ grams) and gestational age (immature $=28-32$ weeks, extreme $=<28$ weeks) 
prematures. So today the "threshold of viability" is between $400-500$ grams natal weight and 22-23 weeks gestational age.

Thus there is a mayor problem for proper respiratory management of these extreme and very less weight prematures. In 25-28 weeks gestational age range the best would be to avoid invasive ventilation, oxygen therapy and prolonged endotracheal intubation; but in this subpopulation the early and elective administration of surfactant at birth in delivery room is highest recommended for its tenso-active effect in the immature lung; after this we must to try the subsequent early extubation in the NICU applying a nasal continuous expiratory pressure in the airway (nCPAP), or non invasive ventilation techniques (NIV), and administering caffeine to prevent these reintubation for the frequent premature apnoeas. This strategy (figure 3) has shown a very significant decrease morbidity and mortality, hospital stay and health costs related to the presence of neonatal RDS and the subsequent impact on his mayor respiratory after-effect: the bronchopulmonary dysplasia (BPD) or chronic neonatal lung disease (CLD), (Kilbride et al,2003).

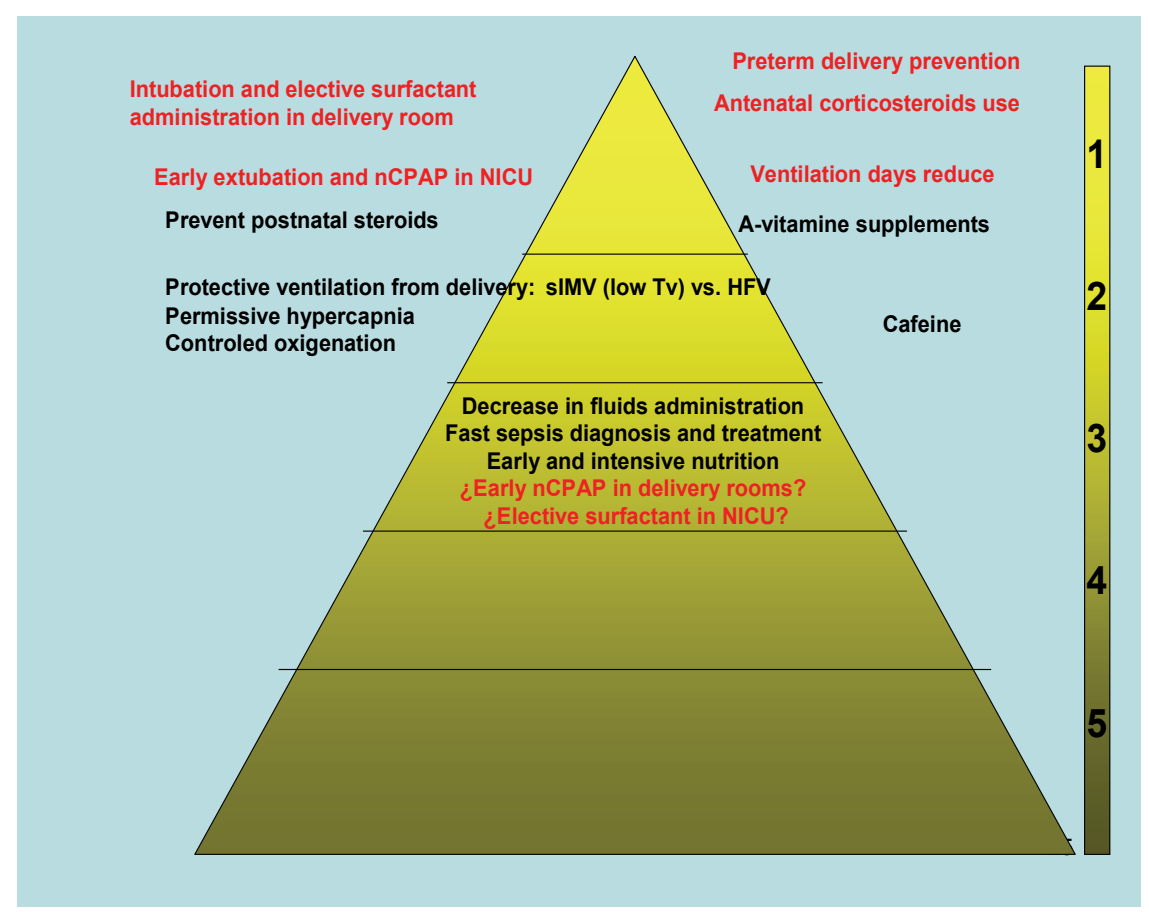

Fig. 3. Potentially beneficial practices (PBP) based on the best scientific evidence available (evidence grades 1-5), for the prevention of chronic lung disease of prematurity or bronchopulmonary dysplasia in the NICU. Source (as amended): "Evidence-Based Quality Improvement in Neonatal and Perinatal Medicine: The NIC / Q 2000 Experience" (Kilbride et al, 2003). nCPAP (nasal continuous expiratory airways pressure); sIMV (synchronized invasive mechanical ventilation); Tv (tidal volume); HFV (high frequency ventilation)

In the last ten years the early nCPAP or NIV use from the VLBW newborn birth in the delivery room, that it has been protocol in our hospital since 2003 (figure 4), have meant a 
change of neonatal cardiopulmonary resuscitation in delivery room and subsequent of respiratory support modality in major world NICU (Buron et al, 2006; American Heart Association, 2005). However, although it's unclear whether this early elective use has a beneficial effect, mainly by avoiding the most common squeal of extreme prematurity the BPD o CLD, or if it causes an increase in the subsequent need for mechanical ventilation and the later pneumothorax incidence, because it delay the classical treatment of RDS, that although it's more invasive, it has proven its effectiveness and efficiency in the last decades (Carlo et al, 2002; Vital \& Arnold, 2005).

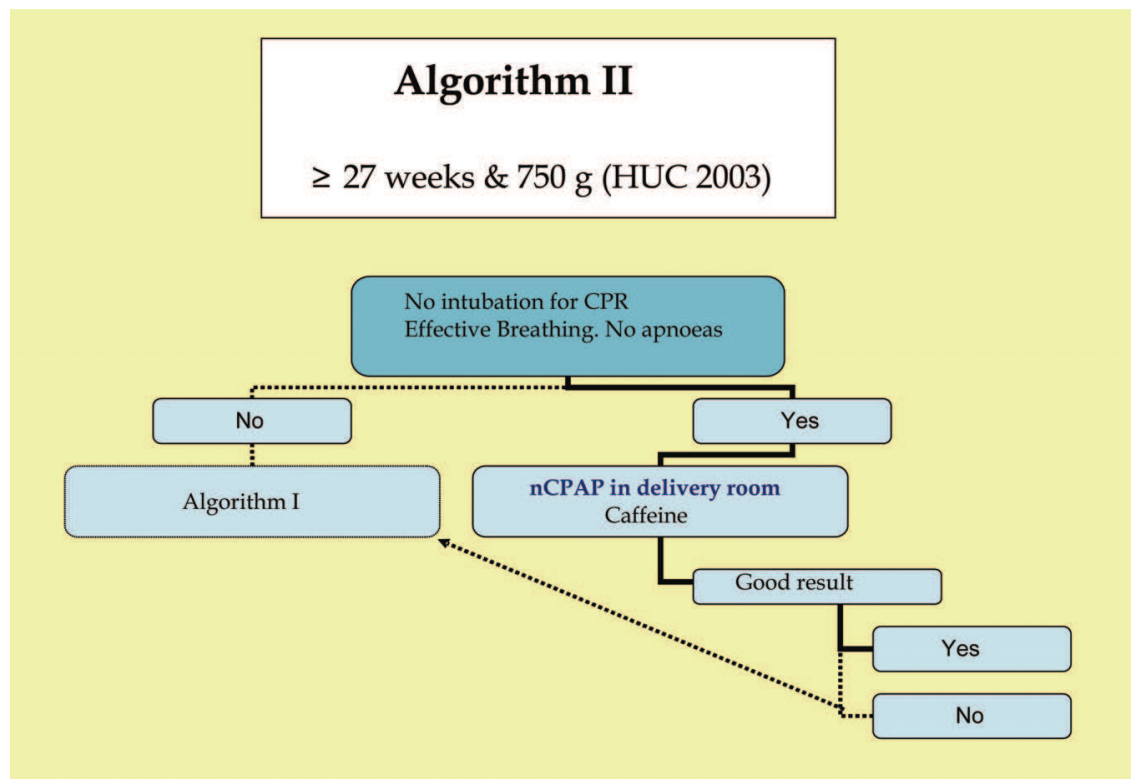

Fig. 4. Non invasive ventilator support in VLBW premature from delivery room to NICU (HUC protocol, 2003). Weeks (gestational age); g (grams birth weight); CPR (cardiopulmonary resucitation); nCPAP (nasal continuous positive airways pressure)

Do to these evidences, since 2003 we have also the "Algorithm I" (figure 5) for the extreme preterm less than 27 weeks and 750 grams, which provides for elective intubation and surfactant administered in delivery room at an early stage lung (at birth 15 minutes in delivery room or after a mayor stabilization at the first half hour of life in NICU). At the same time, the "Algorithm II" protocol includes the criteria for failure of nCPAP, or NIV if it was indicated, this is an emergency situation in which we must proceed fasting to his immediate intubation and selective surfactant administration, if there are diagnostic criterions for RDS, carried on an invasive ventilation protective synchronized support (initially assisted or controlled -A/C-, high frequency ventilation -HFV- if it's need a rescue technique, and later guaranteed volume -GV- and sometimes support pressure ventilation -SPV- too), while we maintained a strategy of "permissive hypercapnia" and a minimum "functional oxygenic ranges" through continuous monitoring of end-tidal $\mathrm{CO}_{2}$ $\left(\mathrm{ETCO}_{2}\right)$ and skin crosswise oxygen saturation $\left(\mathrm{SatO}_{2}\right)$, respectively (Woodgate \& Davies, 2001). 


\section{Algorithm I}

\section{$<27$ weeks \& $750 \mathrm{~g}$ (HUC 2003)}

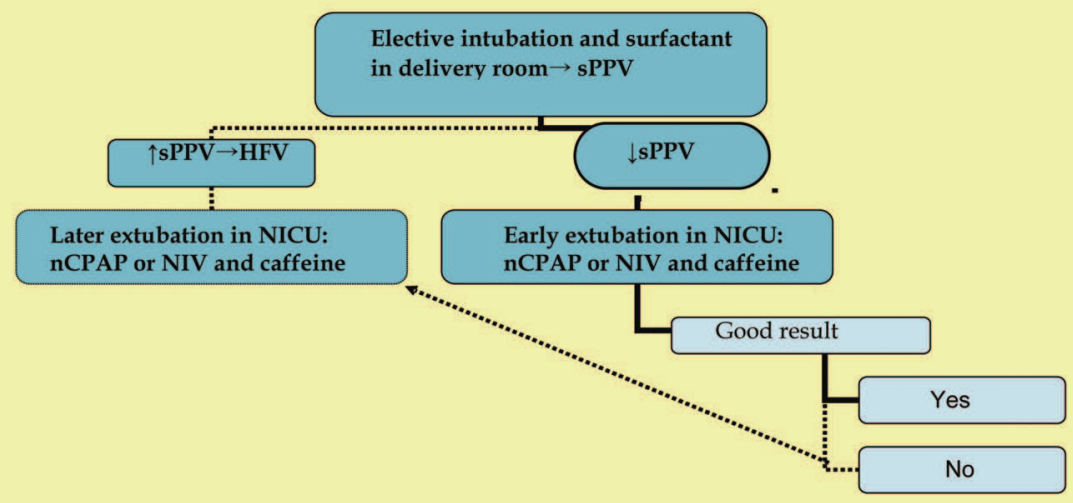

Fig. 5. VLBW infants invasive respiratory support in delivery room and NICU (HUC, protocol 2003). Weeks (gestational age); g (grams of birth weight); sPPV (synchronized positive pressure ventilation) ; HFV (high frecuency ventilation; $\uparrow$ sPPV (high sPPV parameters); $\downarrow$ sPPV (low sPPV parameters); nCPAP (nasal continuous positive airways pressure); NIV (non invasive ventilation)

Many currently studies are researching others preventives respiratory postnatal measures: the possibility of administering the surfactant aerosol (Down \& Sinha, 2008); new synthetic surfactants; novel protective strategies for invasive ventilation (Morley et al, 2008; Stevens et al, 2007); the more safest range of oxygen saturation; the prophylactic use of inhaled nitric oxide (iNO), (Barrington et al, 2007); an appropriate pattern of postnatal corticosteroids administration to achieve early extubation (Giagliardi et al, 2007; Watterberg, 2006); the use of several pharmacologic agents as the inositol (Howlett \& Ohlsson, 2003), the antiinflammatory recombinant protein "Clara" CC10 (Levine et al 2005), the antioxidant superoxide dismutase (Davis et al 2003); an optimal electrolyte balance; the early and intensive parenteral nutrition and enteral; and a fast diagnosis and treatment of chorioamnionitis and neonatal sepsis (Fahley et al, 2008). Some of these strategies, mainly the combination of the three last measures, appear to be effective enough to reduce the incidence of BPD (Bhandari \& Bhandari, 2009; Geary et al, 2008). Therefore we are implementing some of them in our NICU.

However all these postnatal actions, including the newer ventilation and protective pharmacological interventions, are probably later to be adequately effective in the prevention of premature BPD. The best would be the prenatal preventive interventions, where the prevention of preterm delivery would be more effective, but now it's hardly ever possible (Buhimschi et al, 2006). Thus the single administration of antenatal corticosteroids before premature delivery less than 34 weeks gestation, to achieve fetal lung maturity, is 
now the most effective strategy, but it's to discuss. Other possible preventive measures, such as the maternal administration of antibiotics in suspected chorioamnionitis, the antepartum antibiotic prophylaxis in premature prolonged rupture of the amniotic sac, or the intrapartum penicillin prophylaxis of Streptococcus agalactiae transmission, although there are highly recommended in the clinical practice guidelines, haven't getting to decrease the BPD (Bhandari \& Bhandari V, 2009).

Our experiences is situated in the NICU of HUC, a health level care III-B unit (it's lacking only of ECMO -extracorporeal membrane oxygenation- and cardiac bypass surgery), with 6 open beds and 2 more in an isolation box, that generate more of 300 annual admissions, with an average stay of 7.4 days. Furthermore, we have others two neonatal hospitalization units with 8 medium neonatal cares beds and 10 minimum neonatal cares beds, both with an average of 600 annual admissions more.

We had studied the use of respiratory support techniques and the outcomes in our VLBW newborn during 2002-2008. We had compared them with the national neonatal network SEN1500 (SEN1500, 2010), a Spanish follow-up group of the Spanish Society of Neonatology (SEN, 2010) and the international Vermont Oxford Network (VON, 2010)), in which we participated since 2001 and 2005, respectively; and also with the published outcomes of the NNIS (National Nosocomial Infections Surveillance System Report (NNIS), 2003) and the SHNS (Edwards et al, 2007).

The HUC had an annual average of 2743 live births, with a total of 19198 inpatients in the seven study years. It's the north health area reference center for two level II hospitals in the Santa Cruz de Tenerife Province; both had an annual average of 1000 live births. Therefore our annual average neonatal population was of 3743, with a total of 26198 live births in them seven years. During the study we had 276 inside VLBW (1.4\%), with 117 ELBW (0.6\%), and 24 outside VLBW (none were ELBW); so that the total number attended in our NICU were of 300 VLBW.

We included in our study only 226 VLBW newborn (81.9\%) alive in the HUC with sufficient or uncertain viability ( $\geq 23$ weeks and 400 grams without malformations non compatible with life, non died in delivery room, without criteria for limitation of treatment) and that were available their parents consent. The average weight was $1146 \pm 244$ grams and the mean gestational age $29.5 \pm 24$ weeks; the $47.8 \%$ were male; $19.5 \%$ of pregnancies were in vitro fertilization and $35.4 \%$ multiple pregnancies; $74.3 \%$ were caesarean deliveries; $72.1 \%$ received prenatal corticosteroids and $32.3 \%$ antibiotics.

We collected all the variables into a computerized database, and perform a statistical analysis descriptive and comparative using the SPSS software (+) 15.0.

Our main findings and outcomes were:

1. Delivery room: $10.2 \%$ perinatal hypoxia; $78.8 \%$ CPR with O2 (oximetry preductal 85$92 \%$ at 10 minutes), $58.4 \%$ nCPAP, $46 \%$ non invasive ventilation by mask (inspiratory pressure $15-20 \mathrm{~mm} \mathrm{Hg}$ and expiratory $5-6 \mathrm{~mm} \mathrm{Hg}$ ), 31\% endotracheal intubation and invasive ventilation (tidal $\mathrm{CO}_{2} 35-45$ ), $3.5 \%$ cardiac massage, $1.7 \%$ adrenaline and $8 \%$ elective surfactant $(200 \mathrm{mg} / \mathrm{Kg})$.

2. NICU: CRIB ("Babies Clinical Risk Index) $2.63 \pm 2.90 ; 15 \%$ congenital malformation; $53.5 \%$ RDS criteria, $9.3 \%$ pneumothorax (all after a later invasive ventilation); $7 \%$ early sepsis, $20.8 \%$ nosocomial bacteremia and $4.5 \%$ ventilation-associated pneumonia; $8.8 \%$ BPD and 3.1\% several retinopathy of prematurity (ROP grades $3-5$ ). The $80.5 \%$ needed oxygen ( $\mathrm{FiO} 2>21 \%), 74.8 \%$ nCPAP or $\mathrm{NIV}$ (30.2\% exclusive from the delivery room) 
and caffeine, $66.8 \%$ conventional invasive ventilation (44.6\% for nCPAP or NIV failure) and $26.5 \%$ high frequency ventilation (with a total ventilation rate of 0.21 days/stay days), selective surfactant $41.1 \%, 1.3 \%$ iNO (for pulmonary hypertension) and $9.3 \%$ postnatal corticosteroids (to achieve his extubation and only after two weeks age).

3. At discharge: $79.2 \%$ home and only $2.8 \%$ with home oxygen-therapy and monitor; $3.5 \%$ transferred to another hospital (all for cardiac surgery); and $17.3 \%$ died (1.3\% within 12 hours of life).

We found a large statistical relationship $(\mathrm{p}<0.01)$ for the early nCPAP from delivery room or NIV and the less use of oxygen in the NICU (FiO2 $<0.50$ and mean of 9.7 days) and the lower incidence of BPD. Also was significant $(\mathrm{p}<0.05)$ the lower incidence of severe ROP (grades 3-5).

There was a large significant correlation $(\mathrm{p}<0.001)$ between the risk of death and a gestational age $<24$ weeks, the need for resuscitation at birth with adrenaline and a CRIB $>9$.

Besides the exclusive use of non invasive respiratory support helped the VLBW newborn to achieve faster his early progressive enteral nutrition, non-nutritive sucking at the breast with a close contact "skin to skin" with her mother and finally a mayor breastfeeding: the majority of him received first an enteral nutrition with breast milk, and $50 \%$ were maintained later beyond of his hospital discharge.

When we compared our outcomes with the VON and SEN1500 observed that: in the HUC the obstetrician administered less prenatal corticosteroids and performed a greater number of caesarean; our VLBW newborn had +1 week gestational age, similar mean natal weight, less perinatal hypoxia, intubation and early surfactant in delivery room, but more nCPAP or NIV; less oxygen, more nCPAP and NIV, less surfactant with a lower incidence of RSD, BPD and severe ROP in the NICU, although with a higher incidence of pneumothorax associated with later invasive ventilation when nCPAP or NIV failures; our incidence rate of early sepsis were higher, also the nosocomial bacteremia but it decreased progressively, while those the pneumonia associated-ventilation and the use rate of invasive ventilation remained adequate; at discharge our VLBW newborn had lower length of stay, average weight and very few patients needed home oxygen-therapy and monitor. Furthermore and significantly, we had a high incidence of major congenital malformations.

The main conclusions were that: during the study it was a progressive implementation in our VLBW newborn of early nCPAP or NIV from the delivery room, it helped to reduce the need of oxygen-therapy, the incidence of BPD and severe ROP, but not of pneumothorax associated with a delayed invasive respiratory support and surfactant administration; as well as improving many other aspects related to quality and safety of our patients.

It was evident that the early use of non invasive respiratory support had benefits for our VLBW newborn. But at the same time, our results indicated that we should formalize and better select why patients more premature would to be candidates for elective intubation and early surfactant administered immediately after stabilization in the delivery room or in the NICU.

From then on we have made these corrective actions, which in the last two years have been quite effective and efficient, improving the quality and safety of our VLBW newborn. Although we have not even completed the measures of all indicators of this process that 
fully guarantee it, in 2009 year we have improved dramatically, achieving similar or even superior results to those obtained by the VON: we have increased use of antenatal corticosteroids and decreased number of caesareans; intubate and administer more early surfactant in delivery room or NICU in the smallest premature, select and better ensure early invasive respiratory support halving the incidence of delayed pneumothorax, reducing significantly the incidence of early and late sepsis. We have continued our excellent results for the BDP and ROP; also we have optimized a lot of nutrition and so the $80 \%$ of our VLBW newborn keep the breast milk at discharge.

\section{References}

Abramczyk, M.L. et al (2003). Nosocomial infection in a pediatric intensive care unit in a developing country. Braz J Infect Dis, Vol. 7, No. 6, (December 2003) 375-80, ISSN 1413-8670.

AEP (2010, September): Asociación Española de Pediatría. Retrieved from http://www.aeped.es/

AHA: American Heart Association (2005). Journal of American Heart Association: Neonatal Resuscitation Guidelines. Circulation, Vol. 112, (2005), 188-195.

Alfaleh, K. \& Bassler, D. Probiotics for prevention of necrotizing enterocolitis in preterm infants. Cochrane Database Syst Rev, Vol. 23, No. 1, (January 2008), CD005496.

Aly, H. et al (2005). Is bloodstream infection preventable among premature infants? A tale of two cities. Pediatrics, Vol 115, (2005), 1513-1518, ISSN 00314005.

Bacteriemia zero $1^{\text {a }}$ edición (May 2009). Basado en el proyecto "Keystone ICU" desarrollado por la Universidad John Hopkins (Pronovost, P. et al. $N$ Eng J Med, 2006; 2725: 32). Adaptado al español y publicado por el Ministerio de Sanidad y Consumo Español (actualmente Ministerio de Sanidad y Política Social), la SEMICYUC (Sociedad española de Medicina Intensiva y Unidades Coronarias) y el Departamento de Seguridad del Paciente de la WHO. Retrieved from http://www.seguridaddelpaciente.es/index.php/lang-

es/component/content/article/42-sociedades-cientificas-prof/73-programapara-reducir-las-bacteriemias-por-cateteres-venosos-centrales-en-las-uci-delsns.pdf

Balmer, S.E. \& Wharton, B.A. (1989). Diet and faecal flora of the newborn: breast milk and infant formula. Archives of Disease in Childhood, Vol. 64, (1989), 1672-1677.

Barclay, A.R. et al (2007). J Pediatr Gastroenterol Nutr, Vol. 45, No. 5, (November 2007), 56976.

Barrington, K.J. \& Finer, N.N. (2007). Inhaled nitric oxide for preterm infants: a systematic review. Pediatrics, Vol. 120, No. 5, (November 2007), 1088-99, ISSN 00314005.

Bertini, G. et al (2005). Fluconazole prophylaxis prevents invasive fungal infection in highrisk, very low birth weight infants. J Pediatr 2005; Vol. 147, (2005), 162-165.

Beth, H.S. et al (2001). Nosocomial infection rates in US children's hospitals neonatal and pediatric intensive care units. Am J Infect Control, Vol. 29, (2001), 152-157.

Bhandari, A. \& Bhandari, V. Pitfalls (2009). Problems and progress in bronchopulmonary dysplasia. Pediatrics, Vol. 123, No. 6, (2009), 1562-74, ISSN 00314005. 
Boyce, J.M. \& Pittet, D. For the Healthcare Infection Control Practices Advisory Committee and the HICPAC/SHEA/APIC/IDSA Hand Hygiene Task Force. Guideline for Hand Hygiene in Health-Care Settings. Morb Mort Week Rep, Vol. 51, RR16, (2002), 1-44.

Buhimschi, C.S. et al (2006). Clinical proteonomic: a novel diagnostic tool for the new biology of preterm birth, part I: proteomics tools. Obstet Gynecol Surv, 61 (7): 4816.

Burón, E. \& Grupo de RCP Neonatal de la Sociedad Española de Neonatología (2006). Reanimación del recién nacido. An Esp Pediatr, Vol. 65, No. 5, (November 2006), 470-477, ISSN 1695-4033.

Carlo, W.A. et al (2002). Minimal ventilation to prevent bronchopulmonary dysplasia in extremely-low-birth-weigt infants. J Pediatr, Vol. 141, (2002), 370-375.

Capretti, M.G. et al (2008). Impact of a standardized hand hygiene program on the incidence of nosocomial infection in very low birth weight infants. Am J Infect Control, Vol. 36, No. 6, (August 2008), 430-5.

CDC (September 2010): Centers for Disease Control and Prevention. Retrieved from http://www.cdc.gov

CgestiónE/I (September 2010): Club Excelencia en Gestión. Retrieved from http://www.clubexcelencia.org/

Clerihew, L. et al (2007). Prophylactic systemic antifungal agents to prevent mortality and morbidity in very low birth weight infants. Cochrane Database Syst Rev, Vol. 17, No. 4, (October 2007), CD003850.

Dani, C. et al (2002). Probiotics feeding in prevention of urinary tract infection, bacterial sepsis and necrotizing enterocolitis in preterm infants. A prospective doubleblind study. Biol Neonate. 2002 Aug;Vol. 82, No. 2, (August 2002), 103-8.

Davis, J.M. et al (2003). Pulmonary outcome at 1 year corrected age in premature infants treated at birth with recombinant human CuZn superoxide dismutasa. Pediatrics, Vol. 111, No. 3, (2003), 469-76, ISSN 00314005.

Deshpande, G. et al (2007). Probiotics for prevention of necrotising enterocolitis in preterm neonates with very low birth weight: a systematic review of randomised controlled trials. Lancet, Vol. 369, No. 9573, (2007), 1614-1620.

Deshpande, G. et al (2010). Updated meta-analysis of probiotics for preventing necrotizing enterocolitis in preterm neonates. Pediatrics, Vol. 125, No. 5, (May 2010 - Epub 2010 Apr 19), 921-30, ISSN 00314005.

Down, S.M. \& Sinha S.K. (2008). Aerolized lucinactant: a potential alternative to intrachacheal surfactant replacement therapy. Expet Opin Pharmacother, Vol. 9, No. 3 (2008), 475-8.

Edwards, A.M. \& Parrett C.A. (2002). Intestinal flora during the first months of life: new perspectives. British Journal of Nutrition (2002), Vol. 88, Suppl. 1, (2002), S11-S18.

Edwards, A.M. et al (2005). Attributable Cost of Nosocomial Primary Bloodstream Infection in Pediatric Intensive Care Unit Patients. Pediatrics, Vol. 115, (2005), 86872, ISSN 00314005.

Edwards, A.M. et al (2007). National Center for Infectious Diseases (NCID). Retrieved from http://www.cdc.gov/ncidod 
Edwards, A.M. et al (2007). National Healthcare safety Network (NHSN) Report, data sumary for 2006, issued June 2007. Am J Infect Control, Vol. 35, No. 5, (June 2007), 290-301.

EFQM (2010, September): European Foundation for Quality Management. Retrieved from http://www.efqm.org/en/

EuroNeoNet: European Neonatal Network (2010, September). Retrieved from http://www.euroneostat.org/paginas/publicas/euroneo/euroNeoNet/index.html

ESPNIC (2010, September): European Society of Paediatric and Neonatal Intensive Care. Retrieved from http://www.espnic.org/

EVALUACIONEFQM (2010, September). Retrieved from http://www.evaluacionefqm.com/

Fahey, J.O. (2008). Clinical management of intra-amniotic infection and chorioamnionitis: a review of the literature. J Mild-wifery Womens Health, Vol. 53, No. 3, (2008), 22735.

Fay, J.P. \& Faries R.N. (1975). The inhibitory action of fatty acids on the growth of E coli. Journal of General Microbiology, Vol. 91, (1975), 233-240.

Finer, N.N. et al (2004) Delivery room continous positive airway pressure/positive endexpiratory pressure in extremely low birth weight infants: a feasibility trial. Pediatrics, Vol. 114, no. 3, (2004), 651-657, ISSN 00314005.

Geary et al (2008). Decreased incidence of bronchopulmonary dysplasia after early management changes, including surfactant and nasal continuous positive airway pressure treatment at delivery, lowered oxygen saturation goals, and early amino acid administration: a historical cohort study. Pediatrics, Vol. 121, No. 1, (2008), 89-96, ISSN 00314005.

Geffers, C. et al (2008). Incidence of healthcare associated infectios in high-risk neonates: results Fromm the German surveillance system for very-low-birth weight infants. J Hosp Infect, Vol. 68, (2008), 214-221.

Giagliardi, L. et al (2007). Antenatal steroids and risk of bronchopulmonary dysplasia: a lack of effect or case of over-adjustment? Paediatr Perinat Epidemiol, Vol. 21, No. 4, (2002), 347-53.

Girou, E. et al (2002). Efficacy of hand rubbing with alcohol-based solution versus standard hand washing with antiseptic soap: randomized clinical trial. British Medical Journal, Vol. 325, (2002), 362-6.

Guía de la calidad (September 2010) Retrieved from http:/ / www.guiadelacalidad.com/modelo-efqm.php?op=11

Grohskopf, L.A. et al (2002). Pediatric Prevention Network. A national point-prevalence survey of pediatric intensive care unit-acquired infections in the United States. $J$ Pediatr, Vol. 140, No. 4, (2002), 432-8.

Healy, C.M. et al (2005). Impact of fluconazole prophylaxis on incidence and outcome of invasive candidiasis in neonatal intensive care unit. J Pediatr, Vol. 147, (2005), 166171.

Howlett, A. \& Ohlsson, A. (2003). Inositol for respiratory distress syndrome in preterm infants. Cochrane Database Syst Rev, Vol. 4, (2003), CD000366.

Infectious Diseases Society of America (2009). Clinical Practice Guidelines for the Management of Candidiasis (2009 Update). Clinical Infect Diseases, Vol. 48, (January 2009), 503-35. 
ISTAC: Instituto Canario de Estadística (2010). Retrieved fromhttp://www2.gobiernodecanarias.org/istac/

Kaufman, D.A. \& Manzoni, P. (2010). Strategies to prevent invasive candidal infection in extremely preterm infants. Clin Perinatol, Vol. 37, No. 3, (September 2010), 611-28.

Kilbride, H.W. et al (March 2003). Evaluation and Development of Potentially Better Practices to Prevent Neonatal Nosocomial Bacteraemia. Evidence-Based Quality Improvement in Neonatal and Perinatal Medicine: The NIC/Q 2000 Experience. Pediatrics, Vol. 111, Suppl., (March 2003), e504-e518. Retrieved from http://pediatrics.aappublications.org/content/vol111/issue4/\#SUPPLSE1

Kitajima, H. et al (1997). Early administration of Bifidobacterium breve to preterm infants: randomised controlled trial. Arch Dis Child Fetal Neonatal Ed, 1997 Mar; Vol. 76, No. 2, March 1997), F101-7.

Kugelman, A. et al (2007). Nasal intermittent mandatory ventilation versus nasal continuous positive airway pressure for respiratory distress syndrome: a randomized, controlled, prospective study. J Pediatr, Vol. 150, No. 5, (2007), 521-6.

Levine, C.R. et al (2005). The safety, pharmacokinetics, and anti-inflammatory effects of intrachateal recombinant human Clara cell protein in premature infants with respiratory distress syndrome. Pediatr Res, Vol. 58, No. 1, (2005), 15-21.

Saima, L. Strategies for prevention of nosocomial sepsis in the neonatal intensive care unit. Curr Opin Pediatr, Vol. 18, 101-106.

Moracho, O. (2003). Calidad hospitalaria: modelo de excelencia EFQM del Hospital de Zumarraga, Ozakidetza (Servicio Vasco de Salud). "Jornada Signo", Hospital Ramón y Cajal, Madrid, Marzo 2003.

Morley, C.J. et al (2008). CPAP or intubation at birth for very preterm infants. New Engl J Med, Vol. 358, No. 7, (2008), 700-8.

NHSN (September 2010): Nacional Healthcare Safety Network (CDC- NHSN). Retrieved from http://www.cdc.gov/nhsn/

NNIS (2003): National Nosocomial Infections Surveillance System (NNIS) Report 2003, data summary from january 1992 trough june 2003. AmJ Infect Control, Vol. 31, No. 9, (June 2003), 481-498.

NCID (September 2010): National Center for Infectious Diseases. Retrieved from http://www.cdc.gov/ncidod

O'Grady, N.P. et al (2002). Guidelines for the prevention of intravascular catheter-related infections. Morb Mort Week Rep, Vol. 51, RR10, (2002), 1-26.

PREVINE (2010, September): Programa específico para la vigilancia y control de la infección nosocomial en los hospitales españoles. Retrieved from http://www.mpsp.org/mpsp/Documentos/inf_nosoc/inf_hos.htm

Raymond, J. \& the European Study Group (2000). Nosocomial infections in pediatric patients: an European, multicenter prospective study. Infect Control Hosp Epidemiol, Vol. 21, (2000), 260-3.

Rogowski, J.A. et al (2001). Economic implications of neonatal intensive care unit collaborative quality improvement. Pediatrics, Vol. 107, (2001), 23-9, ISSN 0031 4005 .

Rowin, M.E. et al (2003). Pediatric intensive care unit nosocomial infections: epidemiology, sources and solutions. Crit Care Clin, Vol. 19, No. 3, (2003), 473-87. 
Saiman, L. \& National Epidemiology of Mycosis Survey Study Group (2000). Risk factors for candidemia in neonatal intensive care unit patients. Pediatr Infect Dis J, Vol. $19,(2000), 319-324$.

Saiman, L. (2006). Strategies for prevention of nosocomial sepsis in the neonatal intensive care unit. Curr Opin Pediatr, Vol. 18, (2006), 101-106.

Schanler R.J. (2006). Probiotics and necrotising enterocolitis in premature infants. Arch Dis Child Fetal Neonatal Ed., Vol. 91, No. 6, (2006), F395-F397.

Schreiber, M.D. et al (2003). Inhaled nitric oxide in premature infants with the respiratory distress syndrome. N Engl J Med, Vol. 349, (2003), 2099-2107.

SECIP (September 2010): Sociedad Española de Cuidados Intensivos Pediátricos. Retrieved from http:// secip.blogspot.com/

SEN (September 2010): Sociedad Española de Neonatología. Retrieved from http://www.se-neonatal.es/default_principal.asp?idx=\&cidioma=2

SEN1500 (September 2010): Red española de unidades neonatales de resultados y seguimiento de los recién nacidos de muy bajo peso. Retrieved from http:/ / www.se-neonatal.es/default_principal.asp?idx=\&cidioma $=2$

Stevens et al (2007). Early surfactant administration with brief ventilation vs. selective surfactant and continued mechanical ventilation for preterm infant with or at risk for respiratory distress syndrome. Cochrane Database Syst Rev, Vol. 4, (2007), CD003063.

Stover, B.H. \& Pediatric Prevention Network (2001). Nosocomial infection rates in US children's hospitals' neonatal and pediatric intensive care units. Am J Infect Control, Vol. 29, No. 3, (2001), 152-7.

The Joint Commission (September 2010). Retrieved from http://www.jointcommission.org/GeneralPublic/Complaint/sp_qi_review.htm

Urrea, M. et al (2003). Prospective incidence study of nosocomial infections in a pediatric intensive care unit. Pediatr Infect Dis J, 22 (6): 490-4.

Urrea, M. et al (2007). Nosocomial infections in paediatric and neonatal intensive care units. Journal of Infection, Vol. 54, (2007), 212-220.

Vitaly S.H. \& Arnold J.H. (2005). Bench-to-bedside review: Ventilator strategies to reduce lung injury: Lessons from pediatric and neonatal intensive care. Critical Car, (2005), 177-183.

VON (September 2010): International Vermont Oxford Network for improvement the quality and security of the medical assistance to the newborn and families. Retrieved from http:/ / www.vtoxford.org/

Watterberg, K. (2006). Anti-inflammatory therapy in the neonatal intensive care unit: present and future. Semin Fetal Neonatal Med, Vol. 11, No. 5, (2006), 378-84.

WHIKIPEDIA (September 2010): La enciclopedia libre, web de la fundación española Wikimedia. $\quad$ Retrieved from http://es.wikipedia.org/wiki/Fundaci\%C3\%B3n_Europea_para_la_ Gesti\%C3\%B3n_de_la_Calidad

WHO (September 2010): World Health Organization. Retrieved from http://www.who.int/es/

Won, S.P. et al (2004). Handwashing program for the prevention of nosocomial infections in a neonatal intensive care unit. Infect Control Hosp Epidemiol, Vol. 25, No. 9, September 2004), 742-6. 
Woodgate, P.G. \& Davies M.W. (2001). Permissive hypercapnia for the prevention of morbidity and mortality in mechanically ventilated newborn infants. Cochrane Database Syst Rev, Vol. 2, (2001), CDOO2061.

Yokoe, D.S. \& Classen, D. (2008). Introduction: improving patient safety-through Infection Control: a new health care imperative. Infect Control Hosp Epidemiol, Vol. 29, Suppl, (2008), S3-S11. 


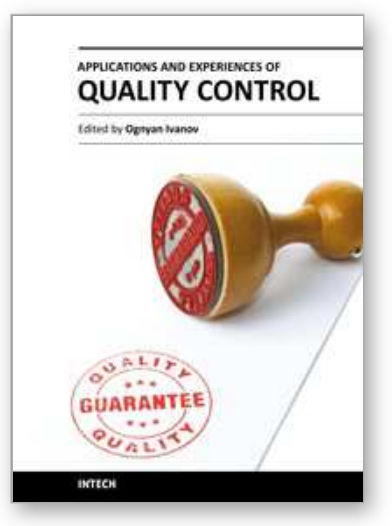

\section{Applications and Experiences of Quality Control \\ Edited by Prof. Ognyan Ivanov}

ISBN 978-953-307-236-4

Hard cover, 704 pages

Publisher InTech

Published online 26, April, 2011

Published in print edition April, 2011

The rich palette of topics set out in this book provides a sufficiently broad overview of the developments in the field of quality control. By providing detailed information on various aspects of quality control, this book can serve as a basis for starting interdisciplinary cooperation, which has increasingly become an integral part of scientific and applied research.

\section{How to reference}

In order to correctly reference this scholarly work, feel free to copy and paste the following:

Fuster-Jorge, P.A., Fernández-Sarabia, J., Delgado-Melián, T., Pérez-Hernández, R., Jiménez-Rivera J.J., Montes de Oca-Afonso M.R., Domenech-Martínez, E. and Sierra-López, A. (2011). Quality and Safety in PICU and NICU: Scoreboard Control and Care Network, Applications and Experiences of Quality Control, Prof. Ognyan Ivanov (Ed.), ISBN: 978-953-307-236-4, InTech, Available from:

$\mathrm{http} / / / \mathrm{www}$.intechopen.com/books/applications-and-experiences-of-quality-control/quality-and-safety-in-picuand-nicu-scoreboard-control-and-care-network

\section{INTECH}

open science | open minds

\section{InTech Europe}

University Campus STeP Ri

Slavka Krautzeka 83/A

51000 Rijeka, Croatia

Phone: +385 (51) 770447

Fax: +385 (51) 686166

www.intechopen.com

\section{InTech China}

Unit 405, Office Block, Hotel Equatorial Shanghai

No.65, Yan An Road (West), Shanghai, 200040, China

中国上海市延安西路65号上海国际贵都大饭店办公楼 405 单元

Phone: +86-21-62489820

Fax: $+86-21-62489821$ 
(C) 2011 The Author(s). Licensee IntechOpen. This chapter is distributed under the terms of the Creative Commons Attribution-NonCommercialShareAlike-3.0 License, which permits use, distribution and reproduction for non-commercial purposes, provided the original is properly cited and derivative works building on this content are distributed under the same license. 